relevant optimization methods are explained). Instead, authors promote simple GRID arithmetic computations. Some of the presented statistical methods are modern but ignore better or similar relevant methods.

This book leaves us with a one-sided, European (mostly English and German) perspective. African, and even Chinese, Indian, Brazilian, Japanese, Russian, polar and ocean perspectives are widely left out. This book suffers from the missing North American and Australian expertise. This matters because the southern biodiversity community has not forgotten the role that the English Kew Gardens played in "biopirating" when Brazil's rubber monopoly got lost to the Commonwealth.

Many of the URLs are very useful. And this is a strength of this book! Unfortunately, they are often promoting short-lived European initiatives, and are cited inconsistently in the chapters.

This book is not so strong on the technical and software concept. XML is mentioned well, but exact software and code details are not given, The PSE (Problem
Solving Environment) is mentioned, but work benches are hardly touched on. E-Science and GRID technology is mentioned but not how it links with GBIF and its data sources and formats. The Open Access code is not well promoted either. Another flaw is the virtual exclusion of Switzerland (being among the European leaders in biodiversity and habitat data).

It is not only that the book editors are from England, but that of the 24 contributors, virtually all are from the EU (mainly Germany, U.K. and Denmark). Such narrow perspectives are not in the best global, national, tax-payers and biodiversity interest. This book clearly shows what European national academies and scientists can produce; but it is almost a lost opportunity and we need to achieve much better if we care about our data heritage and the globe.

FaLK HuetTManN

Biology and Wildlife Department, Institute of Arctic Biology, 419 Irving I, University of Alaska, Fairbanks, Alaska 99775-7000 USA.

\title{
Local Effects of Global Changes in the Himalayas: Manang Nepal
}

By R. Chaudhary, T. H. Aase, O. R. Vetaas, and B. P. Subedi. 2007. Tribhuvan University, Nepal and Uniforskning Bergen, Norway. 199 pages. 35 USD.

This book makes for a stimulating contribution to a popular global heritage site: Manang. It presents an overview of its highly dynamic mountain people, and their direct link with globalization, global climate change and the global community as a whole. The study area, located between 4000 - $7000 \mathrm{~m}$ altitude and presenting one of the highest agricultures in the world, covers the famous Annapurna Conservation Area.

Unfortunately, this informative book, published with strong Norwegian governmental help, goes along happily with the uncritical notion of economic growth (a scheme that by now has put most of the world in shambles). And so, the Norwegian authors state, wrongly: "There is an emerging consensus that globalization promotes economic growth and prosperity throughout the world". Following the new style of NGO - and development aid-publications, it carries "cool concepts" and some "greenwash", but it often lacks solid data and analysis to back it up.

The 19 contributors (12 Nepali, 6 Norwegians and 1 Canadian), describe a harsh region where contract labor is paid 1.4 US\$ per day. Because of a missing ocean nearby, the lack of selenium and iodine results in a high incidence of Kashin-Beck disease and cretinism. If agriculture declines in this part of the world, out-migration goes up, and so does tourism and the income from it.

A strength of this book is that the authors elaborate on the valuable medicinal plant harvest of Nepal and other countries in the Hindu Kush-Himalayas (HKH) region, These studies, financially supported by the international corporation of the Volkswagen Foundation, report on over 60 different species of edible mushrooms (including Morchella species) for commercial export purposes. Other plant species used are, for instance, Taxus baccata and Kutki. "Because of the high global demand and lucrative profit - every age group - were found busy in collecting medical plants". Such an effort cannot be sustainable. Overharvesting increases the price, and thus, the rarity of such plants, which results in a vicious cycle which can easily result in extinction (locally, and even globally).

The Himalayas have approximately 70 big glaciers, which makes for the third largest ice concentration outside of the poles. It supports rivers of global importance such as the Ganges, Brahmaputra and Indus, lifelines for millions of people. Due to man-made climate change; e.g., contamination of the atmosphere through fossil fuel, these glaciers retreat $50 \mathrm{~m} / \mathrm{year}$, The Braca glacier will likely disappear very soon (many informative photos are provided; the book overall shows 17 tables) leaving huge impacts. These facts are in direct disagreement with the opening statement of the book that "It would be more realistic to consider mountains as dynamic, certainly not fragile".

A fascinating book topic deals with the fact that much of the traditional Nepali society is based on coexistence, rather than competition. For instance, Amchis (Tibetan healers) provide health care in villages, free of charge! Further, this book helps to expose "the tragedy of the commons" as a myth, because in many parts of the world, resources have been managed successfully for centuries by indigenous institutions! 
Although agro-pastoralism is the traditional lifestyle of the Manangi, as early as 1784 they had received special trade privileges from King Rana Bahadur Shah, and their import permits were increased during the 1960s by the late King Mahendra. This invokes strong connections with cities abroad such as Delhi, Shillong, Kalkhutta and beyond (e.g., Singapore, Beijing), which are very viable now in times of globalization.

Many of the studies presented are centered on "tsampa, the traditional staple food of the people in Manang". It is made of flour of roasted barley and is served with black tea and yak butter, symbolizing the economic status of the Tibetans.

For agriculture to be successful, good water systems are crucial and thus get well described in the text. "Nutrient management is an important feature of the farming system. No chemical fertilizer is applied". Agricultural systems of Khet (a sophisticate system of cultivated fields) as well as Bari (terraced land) and the traditional Guthi culture are described. Much of the knowledge presented in this book is based, though, on the Dutch geographer van Spengen (1987).

It quickly becomes clear that land tenure is entirely under control of the villagers, but a break with their traditional lifestyle, parampara, has already occurred. Whereas traditionally, buckwheat was the "democratic" food, the effect of global agriculture can be seen easily in the study area by the new crop plants that were used in just the last 20 years (e.g. broccoli, carrot, radish, lettuce, onions, green beans). Absurdly, the area still has a larger dependence on imported rice, widely supported through the World Food Program, although Manang could double the local wheat production when better water systems exist. In addition, the book contributors present recent overbrowsing of forests and tree line. The regeneration of vegetation is affected by humans (also varying by type of slope). One concludes that the current treelines are possibly artificially reduced due to human overuse. (This book does not cover the grazing impacts caused by sheep, goats, yak etc.).

Chartered flights from the Manangi region now provide fresh yak meat to Kathmandu. But traditionally, one yak was locally shared among 4, 8, even 16 families. Today "Tourism and trade has introduced globalised food items such as tinned tuna, pizza, peanuts and biscuits"; this is specially obvious with the strongly increased consumption of dried noodles (enjoyed these days by children and adults several days per week). Manang was opened for tourism in 1977, and the authors belabor the fact that, in academic writing, tourism is widely perceived as negative. But then, the famous Badhe Festival got described by the authors to display a "staged authenticity", representing a recent artifact of bi-locality (having a house in Kathmandu as well as in Upper Madang), commercialized religion and global marketing forces for tourism.
By now, most Manangi live outside of Manang. This means a new definition of citizenship, of oneself, and entirely outside of the traditional passport. The problems associated with this bi-locality are widely discussed. "In 20 years from now, most of the inhabitants of Manang will be living in cities like Kathmandu or Pokhara ...". This book does not describe the phenomenon of Western Union banks (which can be seen in high densities in Kathmandu, and elsewhere).

I like chapter 11 (Ethnomedical Plant Use): it's based on four years of fieldwork, co-authored with a Canadian author. It's also great that Common Property Resource (CPR) theory is explained, and that references are made to the Tribhuvan University Central Herbarium (TUCH). But many chapters are just based on one month of fieldwork or less, and are done by Norwegian village outsiders. The nice chapter 3 , written by a local author, basically carries most of the relevant information presented in this book, with many of the other chapters being repetitive. A major shortcoming in many chapters, specifically some Norwegian ones, is the lack of described methods (e.g. "I conducted a household survey ..."), as well as digital data, GIS and remote sensing maps, URLs and shared online databases (global standard these days). Some chapters present circular logic or consist of an already published M.Sc. thesis. Rather outdated theories from Torstein Veblen (a Norwegian-American economist who published 1899) are promoted as baselines. Statistical validity of many statements made in this book remain doubtful (correlations, vague hypothesis (if at all), result figures of poor quality; some of the facts are conflicting). Most maps appear to be coarse bitmaps, poorly reproduced. Some relevant soil analysis were not completed because of competing lab interests and performances between Norway and Nepal (inter-laboratory comparisons showed no consistency).

The three-page index of scientific, common (English) and local (vernacular) plant names is helpful; but no accepted taxonomy (e.g., ITIS or IPNI) is used (which is confusing for the international audience and when trying to use findings presented). A fourpage general index is provided, as well as a helpful page on acronyms and abbreviations. The reader will appreciate the good collection of literature references (local focus, with many basic North American ones lacking).

"The Intergovernmental Panel on Climatic Change (IPCC) has predicted that the Himalayas in general will get higher annual mean temperatures, more annual precipitation, increased monsoon rainfall, and shrinking areas under snow, ice and permafrost". New grass species; e.g., Calamagrostis, have moved into the area already, probably due to climate change. But instead, some authors state naively that global climate change would mean that Scandinavia's agri- 
culture could simply harvest more (and grasslands would improve), with Iceland having a double amount of sheep. Similar statements on increased productivity and "positive effects" of climate change are made by the authors for their Nepal study area! Another disturbing topic is the missing demand to stop overconsuming and reduce the wasteful use of fossil fuel and contamination of the atmosphere by the global community. Such omissions are no surprise considering that this project is funded by one of the wealthiest nations of the world is among the biggest oil and gas producers (the book receives the general governmental approval through a Foreword by the Norwegian ambassador who visited Manang briefly). Together with the Volkswagen Foundation funding chapters of economic interest (ethnomedicine to be exploited by the western pharmaceutical industry), the academic involvement of Bergen University promoting uncritically all such concepts needs to be seen as 'dubious'.
The reader will easily find other Norwegian views and biases imposed throughout the text; e.g., "the social landscape of Manangi is at the verge of change and towards attaining a new identity" (instead of stating that it will go extinct, creating much human suffering; a path that in times of globalization many other cultures are already on), or that development of the study area would be driven by social factors, not climate ones (although the latter clearly affects income and resources; e.g., water and growing season length). Consequently, this book falls short on key ingredients for all our survival: appropriate social justice, global village and adaptive sustainable management.

FALK HuETtManN

Biology and Wildlife Department, Institute of Arctic Biology, 419 Irving I, University of Alaska Fairbanks Alaska 99775-7000 USA.

\section{MisCELLANEOUS}

\section{A Mountain Year: Nature Diary of a Wilderness Dweller}

By Chris Czajkowski. 2008. Harbour Publishing, P.O. Box 219, Madeira Park, British Columbia V0N 2H0 Canada. 192 pages. 36.95 CDA Cloth.

A Mountain Year by Chris Czajkowski is a delight to read and conjures up all the unspoilt beauty of the northern interior of British Colombia. The book is an illustrated journal of a year spent in a retreat away from the rush and mindless bustle of the busy city.

Czajkowski has spent twenty years up at Nuk Tessli, an isolated wilderness region east of Bella Coola, south of Tweedsmuir Provincial Park and five hundred miles north of Vancouver. There are no roads into the area on the western side of the Coastal Mountains, is known as the Charlotte Uplands. The flora ranged from stunted high altitude forest and rises to sub alpine and krummholz.

When Czajkowski first arrived on her own in 1988, there was no cabin there; she logged some trees with her own hands to build the first one. She used chain saws, ropes skids and block and tackle all hauled in by herself. After three years, two more cabins were built and now naturalists and hikers visit in the summer as paying guests. All that is impressive enough but is by no means all the journal teaches us.

This is a journal illustrated by her pen, pencil and watercolour sketches which are both delightful and informative. She has given us the Latin names of the illustrated flowers but not the authority for the names. This is not a book for identification of the plants to below the species level, they do not give enough detail for that, but as paintings they are very artistic. The illustrations of the birds and animals she observed are sketched and full of life and accurate observation. The sketches give the journal a most personal character. But these illustrations are not the only gifts of this book. Czajkowski is obviously a devoted naturalist and a keen and knowledgeable observer.

The journal takes one through a year in the wilderness, starting at the end of 2004. It conjures up the great sense of silence that can be found in mountain and forests. The minus $22^{\circ} \mathrm{C}$ can almost be felt. This is a hard, tough life she leads and shares with two dogs. But she is attuned to nature and so observant of the atmosphere, the clouds and colours, the animals, birds and flowers that share the environment with her.

She has no electricity and uses her computer only when the sun has powered her photovoltaic system. She chops and drags trees for her fuel and heating and uses candles for light. To get to her cabin she hikes in several miles from where a small plane has deposited her and her luggage. She uses a sled to carry her luggage to the cabin. Having settled in, she has to get her water. For this in winter, she uses a chain-saw to cut through the ice crust on the lake and draws her water through the hole. There is no easy living here.

Day by day she records the weather and the birds that visit her feeders. At the end of February she gets a flight out, after some delays, to shop for supplies, give some talks, and brush up her first-aid in case it is needed by her guests or herself. The guests start arriving with the summer. Some come from overseas and help with the maintenance of the trails, blazing new ones and other chores. All the while Czajkowski records the flowers as they come into bloom, and paints them; lists the birds and observes their behaviour. Struggling at times with swarms of flies and mosquitoes, she leads 